\title{
Evidentiary Review of Screening Infants for Autism
}

\author{
Mary Kay Jones ${ }^{1, *}$ and Lori Lauver ${ }^{2}$ \\ ${ }^{1} 817$ South Irving Avenue, Scranton, Pennsylvania 18505, USA \\ ${ }^{2}$ Pennsylvania State University, 90 Hope Drive, P.O. Box 855, Hershey, Pennsylvania 17033, USA
}

\begin{abstract}
Autism is a severe developmental disorder that affects a child's communication, social, and repetitive behaviors. Typically a child will be diagnosed with autism around the age of three. Identifying an autistic child younger than three can be performed at the child's well visits, through the evaluation of the child's developmental milestones. Multiple screening tools have been developed and used to facilitate the identification of developmental milestones. Currently these tools used are for children aged 18 months and older. There is a need to identify a screening tool or tools to be used for infants, (i.e., under 18 months of age) who fail to achieve developmental milestones. The goal of this evidentiary review is to explore the screening tools for infants between the ages of 9 and 18 months.
\end{abstract}

Keywords: Developmental milestones, assessment tool, well visits, search strategy.

\section{BACKGROUND}

Kanner and Asperger were the first to describe the symptoms of autism [1]. This condition is depicted as a severe developmental disorder portrayed by impairments in social and communication behaviors [2]. A diagnosis of autism is made when a child exhibits abnormalities in three behavioral areas: social development, communication, and repetitive behavior obsessive activities [3]. Today it is seen as a complex disability, sometimes categorized as a childhood neuropsychiatric condition [1].

The cause of autism is unknown. Autism is present for only a small percentage of documented cases, and little is known about how or at what age the first symptoms of autism occur [4]. The increase in the number of diagnoses of autism is possibly due to diagnostic changes such as more active case ascertainment, diagnosis at a younger age, the expansion of the diagnostic criteria, demographic shifts in parental characteristics (such as age and race), and environmental factors [4]. Fombonne [4] notes a dramatic increase in autism over the 25-year period between 1980 and 2005. Autism was initially considered a rare disorder; in 2003, it affected only 3 in 500 individuals [5]. However, by 2009, the rate of autism-affected individuals had increased to 1 in 91 [6].

Coonrod and Stone [7] suggested that by focusing on the promotion of screeners and checklists, autistic traits/characteristics might be identified earlier in infants under the age of 18 months. Several valid and reliable tools are used in screening for autism in children 3

*Address correspondence to this author at 817 South Irving Avenue, Scranton, Pennsylvania 18505, USA; Tel: 570-346-4870;

E-mail: Mxj016@alunmi.jefferson.edu years of age and older [8]. The approved tools are AAMR-Adaptive Behavior Scales, Comprehensive Assessment of Spoken Language (CASL), Behavior Assessment System for Children (BASC-2), and Childhood Autism Rating Scale (CARS). The AAMRAdaptive Behavior Scales is used to evaluate children 3 to 16 years old and focuses on adaptive-behavior characteristics of a child with autism, mental retardation, and/or developmental delays [9]. The CASL is used to evaluate children 3 to 21 years old, and assesses language comprehension, expression, and retrieval [8]. The BASC-2 is used in the evaluation of children 2 to 12 years old. This tool measures adaptive and maladaptive behavior [8]. Lastly, CARS is used to assess autism in children aged 2 and above, and in adults [8].

Such instruments can provide an important alternative to the more detailed Diagnostic and Statistical Manual of Mental Disorders (DSM) type diagnostic approach, but entail a somewhat different set of concerns or constraints. For instance, overdiagnosis may be much less of a concern than underdiagnosis, and time constraints and issues of efficiency are important, as is ease of use and the degree of training required for use.

\section{SIGNIFICANCE}

The significance in early detection is in identifying a child during their most important period of growth for the development of communication, which occurs between 8 and 24 months [9]. The skills developed during this period have been associated with the later learning of receptive and expressive language outcomes, including the use of gestures [10] and symbolic and functional play. The purpose of this early detection is to provide these children a form of 
communication that is clearly understandable. This intervention will assist these children in adapting better in daily living and in reducing stress in parents, as the children may not demonstrate problematic behavior when they can communicate their needs and have these needs accommodated [11]. Several tools exist for assessing autism in children 18 months and older. The difficulty in assessing an infant (i.e., an infant under the age of 18 months) for autism is the lack of assessment tools which have a demonstrated reliability and are valid [12]. Infants age 18 months and younger who are developing normally will be able to perform motor skills which include lying, righting, sitting, crawling, and walking [13]. By assessing infants earlier than 18 months of age, detection of abnormalities in motor skills will be possible [13]. An awareness of these normal and abnormal developmental milestones and an age-appropriate tool might aid in the diagnosis of autism. This knowledge would be valuable for the health care provider [14].

\section{SEARCH STRATEGY}

The search strategy for this evidentiary review utilized the databases of Cumulative Index to Nursing and Allied Health Literature (CINAHL), Medline, PubMed, JamaEvidence, Cochrane Library, and Psychlnfo, and included the years from 2005 to present, with one study from 1998. The key words and word combinations used were autism and infants, autism and screening tools, infant and screening tools, M-Chat and infants, infants and CSBS-DP, infants and ESCS, infants and FYI, infants and Mullen Scale, infants and PEDI, infants and toddler checklist, and communication and autism.

Searches using the above-listed key words and phrases yielded the following results: CINAHL M-Chat and infant 65 articles; infants and CSBS-DP 30 articles; infants and ESCS 49 articles; infants and FYI 34 articles; infants and Mullen Scale 182 articles, and infant and PEDI 1784 articles. A Medline search revealed 811 articles for autism and infants; 3 articles for M-Chat; one article for screening tools and infants; and zero articles for autism and infants. The PubMed search for autism and infants revealed 911 articles, and for autism and infant screening 8 articles. For JamaEvidence, autism resulted in zero articles, and for infants and toddler checklist the results were articles unrelated to autism. Cochrane Library was searched for autism and autism and infant screening, but resulted in zero articles in both instances. Ovid was searched for autism and diagnosis and infant and resulted in 121 articles; autism and infants and screening which resulted in 31 articles, and autism and infants and diagnosis and screening tools provided 2 articles. Lastly, the results found in Psychlnfo for communication and Autism were 82 articles, and for infant toddler checklist 31 articles.

The search included studies involving infants from 6 to 24 months of age. Excluded were studies involving children older than 24 months. All studies comparing or utilizing multiple screening tools were included. Several studies included in the Table of Evidence (TOE) were conducted in other countries: Israel, Northern Taiwan, Australia, and the Netherlands. The screening tools utilized in Israel, North Taiwan, and the Netherlands were converted to their native languages of Hebrew, Taiwanese, and Dutch, respectively. One study in the United States included in the TOE was in both English and Spanish. This study was included to demonstrate the versatility of the screening tool. Three studies that utilized the Early Social Communication Scale were duplicate studies and were similar in the age groups evaluated and the randomization of groups between infants with autism and those who were typically developing.

In the 15 articles in the Table of Evidence (TOE), the focus is to determine the appropriate autism screening tool for infants aged 9 to 18 months. The youngest infant was 6 months old and the oldest child was 88 months old. The mean age and median of the infants was 47 months. The smallest sample study was conducted by Benigno, Bennett, McCarthy, and Smith [14] with 16 participants. The largest sample study was carried out over 3.5 years by Pierce, Carter, Weinfeld et al. [15] in the San Diego, California, area, and consisted of 10,479 one-year-old infants.

\section{Assessment Tools Used for the 9-to-18-month-old Infant and the Developmental Behavior Assessed}

A few of the tools approved for assessing infants are the Communication and Symbolic Behavior Scales Developmental Profile (CSBS-DP), the Early Social Communication Scale (ESCS), First Year Inventory $(\mathrm{FYI})$, Mullens Scales, Parent Observation of Early Markers Scale (POEMS), Child Behaviour Checklist $(\mathrm{CBCL})$, and Pediatric Evaluation of Disability Inventory (PEDI). The CSBS-DP Caregiver Questionnaire evaluates the language skills and symbolic understanding of children aged 6 to 24 months. The 45 items on the questionnaire aim to address children's creation of gestures, words, facial expressions, and 
Potentially relevant reports identified

$$
(n=4145)
$$

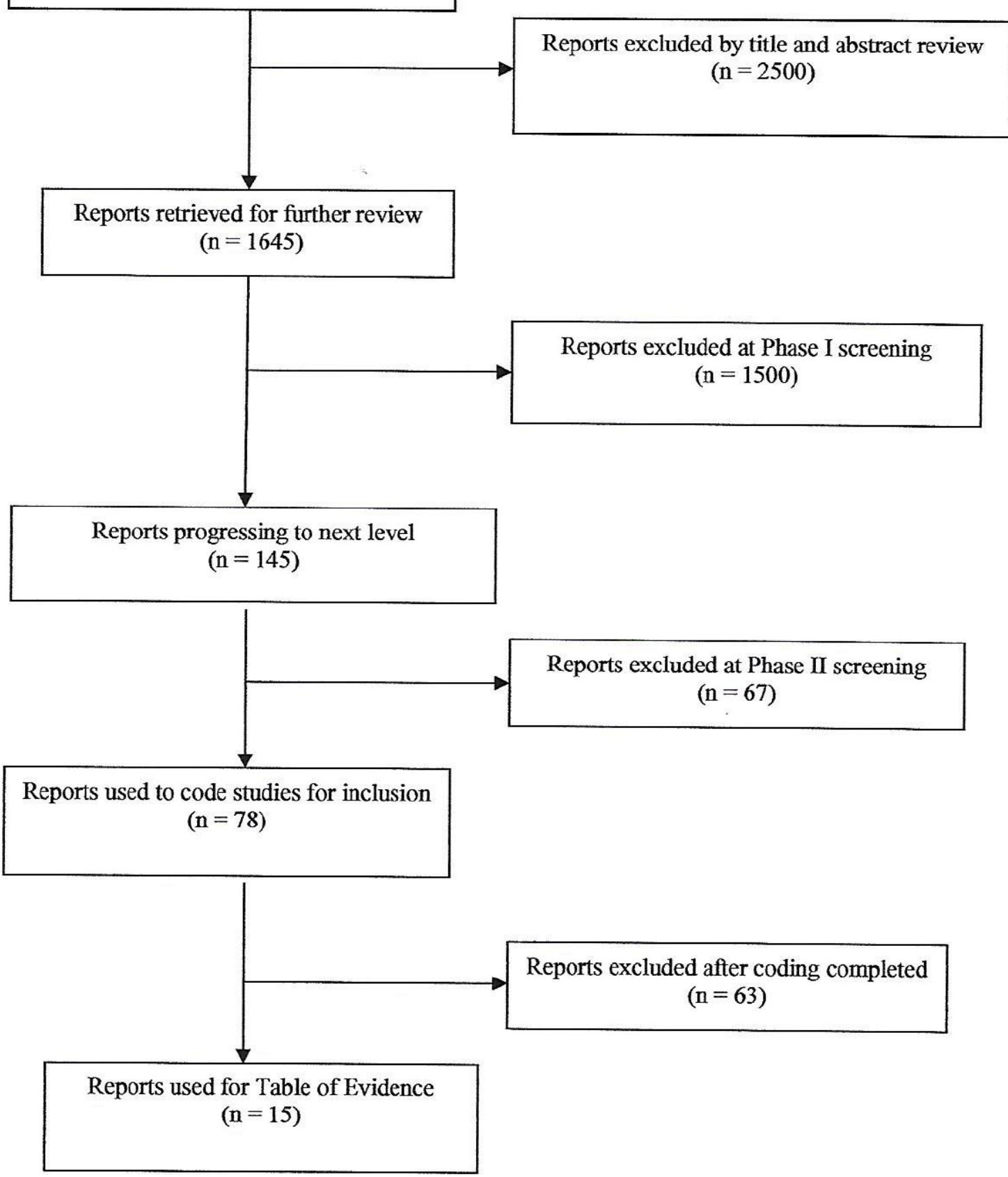

Figure 1: Selection Process for Including Reports in the Table of Evidence.

Table 1: Example of a Few Screening Tools for One-Year-Olds

\begin{tabular}{|c|c|c|c|c|}
\hline $\begin{array}{l}\text { Communication and Symbolic Behavior Scales Developmental Profile } \\
\text { (CSBS-DP) }\end{array}$ & $86-89 \%$ & $75-77 \%$ & 65.3 & .94 \\
\hline First Year Inventory & $88 \%$ & $91 \%$ & .85 & Good \\
\hline Parent Observation of Early Markers Scale (POEMS). & $74 \%$ & $73 \%$ & .21 & Good \\
\hline
\end{tabular}


play behaviors [14]. The CSBS-DP yields a standardized score, with a mean of 100 and a standard deviation of 15 [14]. The ESCS features 25 semistructured interactions employed to extract target behaviors. The tool takes $15-25$ minutes to administer, and relies on the infant's reactions and cooperation. This tool measures the infant's ability to perform joint attention (JA) (i.e., language and temperament). They are evaluated by using the ESCS measure [14]. The FYI is a norm-referenced autism screening tool for 12month-old infants. It affords parents an assortment of response choices instead of limiting them to approving the presence or absence of a behavior [16]. The FYI measures the response to sound or voice, smiling, eye contact, imitation of sounds or actions, and attempts to get the evaluator's attention [17]. The Mullen Scales evaluates five areas of development including gross and fine motor skills, visual reception, and receptive and expressive language [18]. The PEDI was developed to calculate the function status of infants and children [19]. This tool measures the infant's eye gaze, response to food textures and a hairbrush, playing with toys, and putting on and off clothing [19]. The POEMS is a prospective checklist where the parent observes 61 behaviors. This tool can be utilized with infants as young as one month old, and measures gaze from object/toys to a face, imitates a voice/sound, and pointing [20]. The $C B C L$ is utilized to identify maladaptative behaviors. It measures communication, social interactions, play activity, and restrictive and repetitive behaviors [21].

\section{Similarities in Screening Tools}

The common dependent variables are as follows: (a) gaze from object to either parent or researcher, which was identified in eight studies; (b) voice/sound imitation, which was present in five studies; (c) pointing, found in four studies; and (d) spitting out different foods, which was measured in only one study. In 11 of the 15 studies, toys were the common independent variables. Three studies that utilized the ESCS were duplicate studies and were similar in age groups evaluated and the randomization of groups between infants with autism and those who were typically developing.

\section{Differences in Screening Tools}

The tools utilized in the TOE studies assess different developmental milestones. The CBCL assesses the infant's behavior. CSBS-DP measures different developmental milestones and communicative competence. Communicative competence is defined as language proficiency [22]. ESCS evaluates nonverbal communication abilities. Nonverbal communication is defined by how one individual communicates with others using one of the following: (a) facial expressions, such as happiness or annoyance; (b) space, such as standing in close proximity; (c) excessive touch or lack of touch; (d) appearance, which includes the way we dress and how a person defines him- or herself; (e) either hurrying or always late; and ( $f$ ) the tone and moderation of voice [23]. Mullens differs from the other tools in that it, assesses verbal and nonverbal language and motor and perceptual abilities. PEDI analyzes functional capabilities.

\section{Reliability and Validity of Autism Screening Tools}

The results of a study by Eadie, Ukoumunne, Skeats et al. [24] utilizing the CSBS-DP Behaviour Sample and Infant-Toddler Checklist confirmed the validity and reliability of the tools. This finding was confirmed through both the findings of Eadie Ukoumunne, Skeats et al. and the results of the positive predictor value [15] in a study of 10,479 oneyear-old infants. The predictive validity of the CSBS-DP supports the use of this tool as a first-line screener [25]. Chiang, Soong, Lin, and Rogers [26] Taiwan study utilized the ESCS with three groups of infants. The groups were autistic infants between 18 and 20 months of age and typically developing infants aged 13 to 15 months. The results of this study verified the validity and reliability of the tool. These results were similar to a previous study conducted by Mundy, Sigman, Ungerer, and Sherman [27] which focused on the nonverbal skills of young autistic children compared to those of a typically developing child. Goldberg, Jarvis, Osann et al. [28] also confirmed the validity and reliability of the ESCS by comparing autistic children developmentally to their younger non-autistic sibling and to a typically developing child. The results of this study confirmed that younger siblings of an autistic child are at risk for developing autism [28]. This study confirmed the concurrent validity of the $\mathrm{FYI}$ for identifying one-year-old infants who are at risk for social-communication disorders when statistically compared to the results of the Autism Observation Scale for Infants (ASOI) [16]. The construct validity of the FYI was examined by a retrospective method of viewing parent responses. The data obtained confirmed utilization of the FYI tool is appropriate when assessing one-year-olds [17]. The study using the 
POEMS assessment tool was its first test for validity. The predictive validity of the POEMS assessment tool demonstrated validity, distinguishing at-risk infants from 3 to 24 months of age correctly, and assessed the infant as autistic, versus those independently diagnosed with autism at 36 months of age [20]. The Mullens Scale verified a solid concurrent validity with a similar assessment tool for language, motor, and cognitive development [18]. Convergent validity of the Mullens Scale was investigated in 53 children with autism spectrum disorder and 19 children with nonspectrum diagnoses. Data results demonstrated good convergent validity scores for nonverbal and verbal profiles [29].

\section{IMPLICATIONS}

Based on this evidentiary review, several autism assessment tools have been identified as appropriate for use during an infant's well exam. Currently, the diagnosis of autism is limited by the lack of an evidence-based protocol for infants between the ages of 9 and 18 months [30]. The need at present is for a research-tested early-screening instrument that is both sensitive and specific to autism [30]. There is promising important research that emphasizes the clear benefits of identifying the traits/characteristics of autism in infants aged 9 to 18 months.

Early, intensive intervention can considerably improve the infant identified with autism symptomology [30]. Early intervention has demonstrated positive improvement for children with autism, e.g., in the area of communication. This demonstration of improvement warrants widespread practice of early intervention [30]. Because of these improvements realized in infants participating in early intervention, an urgent need exists for the identification, on a broader scale, of infants with traits and characteristics of autism. The earlier these infants can be identified and treated, the more improved the long-term outcome [31].

\section{SUMMARY}

Autism traits and characteristics can be identified in an infant just a few months old. Yet the American Academy of Pediatrics recommends observational screenings at $9,18,24$, and 30 months of age, and screenings with using an approved assessment tool at 18 and 24 months of age if traits or characteristics are present. The evidentiary review of the fifteen articles in the TOE discussed similarities and differences between the studies and also age-appropriate assessment screening tools. The recommendation of evaluating infants at their one-year-old well exam with an ageappropriate tool would benefit the infant with the prompt institution of early intervention. Early intervention has demonstrated to improve the overall symptoms of autism.

\section{REFERENCES}

[1] Baron-Cohen S. Autism research into causes and intervention. Pediatr Rehabil 2004; 7(2): 73-78. http://dx.doi.org/10.1080/13638490310001654790

[2] Toth K, Dawson G, Meltzoff AN, Greenson J, Fein D. Early social, imitation, play, and language abilities of young nonautistic sibling of children with autism. J Autism Dev Disord 2007; 37(1): 145-157. http://dx.doi.org/10.1007/s10803-006-0336-2

[3] World Health Organization. International Classification of Diseases, $10^{\text {th }}$ ed., 2002. Geneva, Switzerland. Available from: http://www.who.int/classifications/icd/en/

[4] Fombonne E. Epidemiology of autistic disorder and other pervasive developmental disorder. J Clin Psychiat 2005; 66: 3-8.

[5] Fombonne E. Epidemiology of pervasive developmental disorders. Trends in Evidence-Based Neuropsychiatry 2003; 5(1): 29-36.

[6] Kogan MD, Blumberg SJ, Shieve LA, et al. Prevalence of parent-reported diagnosis of autism spectrum disorder among children in the US, 2007. Pediatrics 2009; 124: 13951403.

http://dx.doi.org/10.1542/peds.2009-1522

[7] Coonrod E, Stone W. Screening for Autism in Young children, in Handbook of Autism and Pervasive Developmental Disorders, Hoboken, Wiley, 2005; pp. 707729.

http://dx.doi.org/10.1002/9780470939352.ch1

[8] Matson JL, Wilkins J, Fodstad JC. The validity of the baby and infant screen for children with autism traits: part 1 (BISCUIT: part 1). J Autism Dev Disord 2011; 41: 1139-149. http://dx.doi.org/10.1007/s10803-010-0973-3

[9] Reilly S, Wake M, Bavin EL, et al. Predicting language at 2 years of age: a prospective community study. Pediatrics 2007; 120(6): e1441-49.

http://dx.doi.org/10.1542/peds.2007-0045

[10] Capone NC, McGregor KK. Gesture development: a review for clinical and research practices. J Speech Lang Hear Res 2004; 47: 173-186.

http://dx.doi.org/10.1044/1092-4388(2004/015)

[11] Wong VC, Kwan QK. Radomized controlled trial for early intervention for autism: a pilot study of the autism 1-2-3 Project. J Autism Dev Disord 2010; 40(6): 677-688. http://dx.doi.org/10.1007/s10803-009-0916-z

[12] Matson J, Dempsey T, loVullo S, Wilkins J. The effects of intellectual functioning development of infants at risk for autism spectrum disorders. J Autism Dev Disord 2012; 42(1): 13-22. http://dx.doi.org/10.1007/s10803-011-1208-y

[13] Teitlebaum P, Teitlebaum O, Nye J, Fryman J, Maurer RG Movement analysis in infancy may be useful for early diagnosis of autism. P Natl Acad Sci 1998; 95(23): 1398213987.

http://dx.doi.org/10.1073/pnas.95.23.13982

[14] Benigno JP, Bennett JL, McCarthy JW, Smith, JL. Situational and psychosocial factors mediating coordinated joint attention with augmentative and alternative communication 
systems with beginning communicators without disabilities. Augment Altern Commun 2011; 27(2): 67-76. http://dx.doi.org/10.3109/07434618.2011.580779

[15] Pierce K, Carter C, Weinfeld M, et al. Detecting, studying, and treating autism early: the one-year well-baby check-up approach. J Pediatr 2011; 159(3): 458-465.e1-6.

[16] Ben-Sasson A, Carter AS. The application of the first year inventory for ASD screening in Israel. J Autism Dev Disord 2012; 42(9): 1906-1916. http://dx.doi.org/10.1007/s10803-011-1436-1

[17] Watson LR, Baranek GT, Crais ER, Reznick JS, Dystra JR, Perryman T. The first year inventory: retrospective parent responses to a questionnaire desiged to identify one-yearolds at risk for autism. J Autism Dev Disord 2007; 37(1): 4961. http://dx.doi.org/10.1007/s10803-006-0334-4

[18] Landa R, Garrett-Mayer E. Development in infants with autism spectrum disorders: a prospective study. J Child Psychol Psyc 2006; 47(6): 629-638. http://dx.doi.org/10.1111/j.1469-7610.2006.01531.x

[19] Wassenberg-Severijen JE, Custers JW, Hox JJ, Vermeer A, Helders PJ. Reliabilty of the dutch pediatric evaluation of disabilty inventory (PEDI). Clin Rehabil 2003; 17(4): 457-462. http://dx.doi.org/10.1191/0269215503cr634oa

[20] Feldman M, Ward R, Savona D, et al. Development and initial validation of a parent report measure of the behavioral development of infants at risk for autism spectrum disorders. J Autism Dev Disord 2012; 42(1): 13-22. http://dx.doi.org/10.1007/s10803-011-1208-y

[21] Hartley SL, Sikora DM, McCoy R. Prevalence and risk factors of maladaptive behaviour in young children with autistic disorder. J Intellect Disabil Res 2008; 52(10): 819-829. http://dx.doi.org/10.1111/j.1365-2788.2008.01065.x

[22] Bagaric V, Mihaljevic-Djigunovic J. Defining Communication Competence. Metodika 2007; 8(14): 94-103.

[23] Burggraf-Torppa J. Nonverbal Communication: Teaching Your Child the Skills of Social Success. The Ohio State University Family and Consumer Sciences 2009; 1-3.
[24] Eadie PA, Ukoumunne O, Skeat $J$, et al. Assessing early communication behaviours: structure and validity of the Communication and Symbolic Behaviour ScalesDevelopmental Profile (CSBS-DP) in 12-month-old infants. Int J Lang Commun Disord 2010; 45(5): 572-585. http://dx.doi.org/10.3109/13682820903277944

[25] Wetherby AM, Goldstein H, Cleary J, Allen L, Kublin K. Early identification of children with communication disorders. Infant Young Child 2003; 16(2): 161-174. http://dx.doi.org/10.1097/00001163-200304000-00008

[26] Chiang $\mathrm{CH}$, Soong WT, Lin TL, Rogers SJ. Nonverbal communication skills in young children with autism. J Autism Dev Disord 2008; 38: 1898-1906. http://dx.doi.org/10.1007/s10803-008-0586-2

[27] Mundy P, Sigman J, Ungerer J, Sherman, T. Defining the social deficits in autism: the contribution of non-verbal communication measures. J Child Psychol Psyc 1986; 27(5): 657-669.

http://dx.doi.org/10.1111/j.1469-7610.1986.tb00190.x

[28] Goldberg WA, Jarvis KL, Osann K, et al. Brief report: early social communication behaviors in the younger siblings of children with autism. J Autism Dev Disord 2005; 35(5): 657664.

http://dx.doi.org/10.1007/s10803-005-0009-6

[29] Bishop SL, Guthrie W, Coffing M, Lord C. Convergent validity of the Mullen Scales of Early Learning and the differential ability scales in children with autism spectrum disorders. Am J Intellect Dev Disabil 2011; 116(5): 331-343. http://dx.doi.org/10.1352/1944-7558-116.5.331

[30] Bryson SE, Rogers SJ, Fombonne E. Autism spectrum disorders: early detection, intervention, education, and psychopharmacological management. Can J Psyc 2003; 48(8): 506-516.

[31] Matson JL, Wilkins J, González M. Early identification and diagnosis in autism spectrum disorders in young children and infants: how early is too early? Res Autism Spect Dis 2008; 2: 75-84.

http://dx.doi.org/10.1016/j.rasd.2007.03.002

\section{DOI: http://dx.doi.org/10.6000/2292-2598.2015.03.03.1}

(c) 2015 Jones and Lauver; Licensee Lifescience Global.

This is an open access article licensed under the terms of the Creative Commons Attribution Non-Commercial License (http://creativecommons.org/licenses/by-nc/3.0/) which permits unrestricted, non-commercial use, distribution and reproduction in any medium, provided the work is properly cited. 